\title{
BIO-APPLICABLE METAL NANOPARTICLES
}

\author{
Vít VYKOUKAL ${ }^{1}$, Radka DOPITOVÁ ${ }^{1}$, Martin POLÁK ${ }^{1}$, Jiří NOVÁČEK ${ }^{1}$ \\ ${ }^{1}$ Ceitec MU - Central European Institute of Technology Masaryk University, Brno, Czech Republic, EU \\ iiri.novacek@ceitec.muni.cz
}

https://doi.org/10.37904/nanocon.2020.3736

\begin{abstract}
Metal nanoparticles find wide application potential in the biological research due to their unique optical, magnetic, electrical properties. Utilization of the nanoparticles prepared by chemical synthesis for biological research is limited by its solubility in water and toxicity. One potential solution to overcome this limitation is encapsulation of metal nanoparticles into protein or lipidic shell.
\end{abstract}

Apoferritin is highly symmetric $12 \mathrm{~nm}$ protein cage composed of 24 apoferritin monomers which forms hollow structure with $8 \mathrm{~nm}$ cavity. Protein shell specifically interacts with the receptor on the cell membrane which facilitates uptake of the apoferritin from the extra-cellular environment into the cell. Due to the high stability of the protein cage and inherent capacity to encompass metal nanoparticles, apoferritin is widely focused as a potentionally optimal and general system for delivery of the metal nanoparticles into the organism.

In addition, apoferritin can be also used as a nanoreactor for the nanoparticle production. We have generated a set of different nanoparticles encapsulated in apoferritin cage which we have intended to use as a label for structural and cellular biology research by cryo-electron microscopy. Here, we show that despite the $8 \mathrm{~nm}$ cavity, single 6-8 nm nanoparticle is not formed inside apoferritin cage. Instead, larger number of $2 \mathrm{~nm}$ or smaller nanoparticles is present inside apoferritin reducing overall number of atoms which can be incorporated into the molecule and thus the attainable contrast during electron microscopy imaging. Despite its wide utilization in life-science research, we conclude, that apoferritin derived nanoparticle system is not an optimal labeling probe for cryo-electron microscopy.

Keywords: Apoferritin, metal nanoparticles, cryo-electron microscopy

\section{INTRODUCTION}

Chemical synthesis of metal nanoparticles (NPs) is nowadays progressive field of science. Metal nanoparticles can be produced in miligram-to-gram scale by various methods e. g. reduction of metal salts solution in presence of a surfactant [1-4], thermal decomposition of metal precursors [5-7], or ball milling [8,9]. They have found wide range of applications in electronics [10,11], optics [12], catalysis [13] etc. Furthermore, metal NPs are ideal candidates as contrast agent for life-science electron microscopy research due to the significantly higher electron density in comparison to biological samples. NPs bound to antibody or affinity tag are widely used in imuno-electron microscopy studies for localization of molecules of interest [14,15]. However, a robust system which would allow targeting molecules of interest inside living cell is nowadays not available because NPs are, in general, not taken by a cell and are, in most cases, toxic for cells. Even gold NPs which are declared as bio-compatible and non-toxic are not taken up by cells which limit their application as markers for research on viable biological specimen. Integration of the NP into the cell own shell is one potential approach to overcome this issue. Apoferritin was proposed as an ideal candidate for production of hybrid NPs due to its unique structural and functional properties [16]. 
Apoferritin is a $12 \mathrm{~nm}$ hollow protein complex with $8 \mathrm{~nm}$ in diameter cavity. It forms a tetrahedral cage composed of 24 subunits connected through 14 pores. The structure has six twofold symmetry axes, four threefold symmetry axes, and three fourfold symmetry axes. Apoferritin monomers can withstand exposure to temperatures above $70{ }^{\circ} \mathrm{C}$ and wide $\mathrm{pH}$ range 2.0-10.0. The native protein is composed of two kinds of subunits, heavy and light $(\mathrm{H}$ and $\mathrm{L})$. Apoferritin shell exhibits reversible self-assembling ability. The assembly can be destabilized or even disassociated into monomers under specific conditions which can subsequently be reassembled back to the apoferritin structure. It naturally binds iron, serves as iron storage, and functions in distribution of iron to areas where it is required. The inner cavity is able to absorb around 4500 atoms of $\mathrm{Fe}(\mathrm{III})$ to form ferritin [17].

Previous studies showed possibility to synthesize metal nanoparticles inside of apoferritin cavity. Various works declared monodispersive metal nanoparticles embedded in apoferritin shell [17-19]. Metal nanoparticles in apoferritin cavity can be prepared by two approaches: (A) the apoferritin shell is disassociated into monomers. This monomer solution is combined with metal source solution followed by apoferritin shell reconstruction, dialysis or gel filtration to remove excess metal ions outside of apoferritin cavities. Metal ions trapped into cavity are reduced to form metal nanoparticles; (B) Metal ions enter into the apoferritin cavity through channels, where they are trapped, and the excess of ions outside the apoferritin cage is subsequently removed followed by ion reduction inside the cavities. Herein, we have tested both approaches in order to generate hybrid NP where the apoferritin cage is completely filled with single large nanoparticle made of a defined metal. We have synthesized various types of metal nanoparticles and studied the role of $\mathrm{pH}$ and urea concentration on NP size and localization. We have found out that single large NP is not formed inside the apoferritin cage and instead large number of smaller NPs are present which is probably due to the presence of multiple sites for NP nucleation [20]

\section{EXPERIMENTAL}

\subsection{Characterization and sample preparation}

Transmission electron microscopy (TEM) was performed on Tecnai F20 (FEl, Eindhoven) operating at $200 \mathrm{kV}$ equipped with $4 \mathrm{kx} 4 \mathrm{k}$ CCD camera. $4 \mu \mathrm{l}$ of the sample was applied on a $3 \mathrm{~mm}$ TEM copper grid containing 12 $\mathrm{nm}$ continual carbon film. The sample was incubated for $1 \mathrm{~min}$ on the grid and subsequently wicked away with a filter paper. Sample preparation for negative staining electron microscopy comprised 1 min incubation of 4 $\mu \mathrm{l}$ sample drop on the TEM copper grid supplemented with $12 \mathrm{~nm}$ home-made continual carbon film followed by two round of rinsing the grid in $16 \mu \mathrm{l}$ of $2 \%$ solution of uranyl acetate, and removal of the residual amount of the mixture by filter paper. Finally, the sample was allowed to dry under ambient conditions.

\subsection{Preparation of the apoferritin sample}

Apoferritin was expressed from LF2422 plasmid which contains human $\mathrm{H}$ ferritin chain cloned into pGEX2T with a TEV site instead of a thrombin site (gift from Christos Savva). The plasmid was transformed into chemically competent E.coli BL21(DE3)pLYSS. Cells were plated on plates containing Ampicilin and incubated at $37^{\circ} \mathrm{C}$ overnight. Few colonies were used as starter culture followed inoculation bigger volume of LB Amp medium. Cells were growing at $37^{\circ} \mathrm{C}$ until A600nm $=0.1$ then IPTG $(0.5 \mathrm{mM})$ was added to start apoferritin production overnight at $20^{\circ} \mathrm{C}$. Cells were harvested by centrifugation $\left(4{ }^{\circ} \mathrm{C}, 5000 \mathrm{~g}, 20 \mathrm{~min}\right)$ and the cell pellets were resuspended in lysis buffer (1x PBS, Roche Complete Tablet, 0.5\% Triton X-100, $0.5 \mathrm{mM} \mathrm{TCEP,} \mathrm{pH=}$ 7.4), lysed by sonication and the residual cellular debris were removed by centrifugation. Supernatant was incubated at $4{ }^{\circ} \mathrm{C}$ for $30 \mathrm{~min}$ with GST resin. The mixture was centrifuged and the pellet was washed four times with the wash buffer (1x PBS, $0.5 \%$ Triton X-100, $0.5 \mathrm{mM}$ TCEP) followed by three washes with cleavage buffer ( $50 \mathrm{mM}$ Tris $\mathrm{pH}=7.5,100 \mathrm{mM} \mathrm{NaCl}, 0.5 \mathrm{mM}$ TCEP). The GST-tag was removed by incubation with 1:100 w/w TEV protease overnight. Subsequently, the sample was purified by size exclusion chromatography (Superdex S200). The fractions of central peak were analyzed by SDS PAGE and cryo-electron microscopy. 


\subsection{Metal nanoparticles in apoferritin cavity synthesis and characterization}

Apoferritin was separately mixed with various metal precursors $\left(\mathrm{HAuCl}_{4} \cdot \mathrm{xH}_{2} \mathrm{O}, \mathrm{CuSO}_{4} \cdot 5 \mathrm{H}_{2} \mathrm{O}, \mathrm{K}_{2} \mathrm{PdCl}_{4}\right.$ or $\left.\mathrm{NiCl}_{2} \cdot 6 \mathrm{H}_{2} \mathrm{O}\right)$ in molar ratio $1: 20000$ at $\mathrm{pH} 8.5$ in buffer $\left(0.1 \mathrm{~mol} \cdot \mathrm{dm}^{-3}\right.$, TRIS and $\left.0.15 \mathrm{~mol} \cdot \mathrm{dm}^{-3}\right)$. Reaction mixtures were incubated at laboratory temperature for $24 \mathrm{~h}$ with agitation, and then dialyzed against same buffer $\mathrm{pH} 7.5$ for additional 24 hours. Solution of $\mathrm{NaBH}_{4}$ ( 5 equivalent to metal salt) was added to the reaction mixtures which resulted in immediate change of color to ruby, reddish-brown, dark brown, and black for Au, $\mathrm{Cu}, \mathrm{Pd}$, and $\mathrm{Ni}$, respectively. The reaction scheme is summarized in the Figure 1.

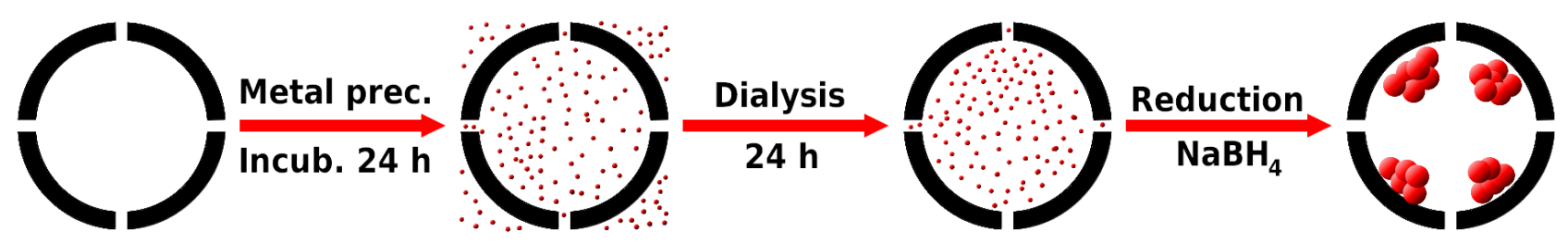

Figure 1 Scheme of apoferritin incubation with metal precursors with subsequent procedures

In case of $\mathrm{HAuCl}_{4}$, the reaction was monitored by TEM during the incubation period which preceded sample reduction. The results of the negative staining EM (TEM-NS) are shown in Figure 2. Apoferritin cavities are primarily without observable metal nanoparticles prior reduction (Figure 2-A). Only few apoferritin particles reveal small seeding gold NPs (Au-NPs, 3-85 $\AA$ ). In addition, irregular gold particles (50-90 $\AA$ diameters) are presents despite the absence of the reducing agent. This phenomenon is probably caused by reduction of $\mathrm{HAuCl}_{4}$ by residual light during sample manipulation although the mixture was kept in dark during the whole reaction.

Addition of reducing agent $\left(\mathrm{NaBH}_{4}\right)$ caused color change of the reaction mixture from original pale yellow to ruby which indicated Au-NPs formation in accordance with TEM observation (Figure 2-B). Au-NPs are primarily located on the outside of the apoferritin cavity and are not removed during dialysis. Nanoparticles are irregular in shape with wide size distribution (20-320 $\AA$ ). As the inner part of the apoferritin is primarily void of NPs, we speculate that the Au atom seeding the NP formation localizes close to the apoferritin pores and blocks the entry of other Au atoms into the cavity in these cases.

In parallel, we have tested whether the accumulation of gold ions inside the cavity increases with the incubation time. We have prolonged the interaction time three times but we have not observed any effect with respect to number or size of the NPs present in apoferritin cavity (Figure 2-C). On the other hand, we have observed increased aggregation of apoferritin in this case.

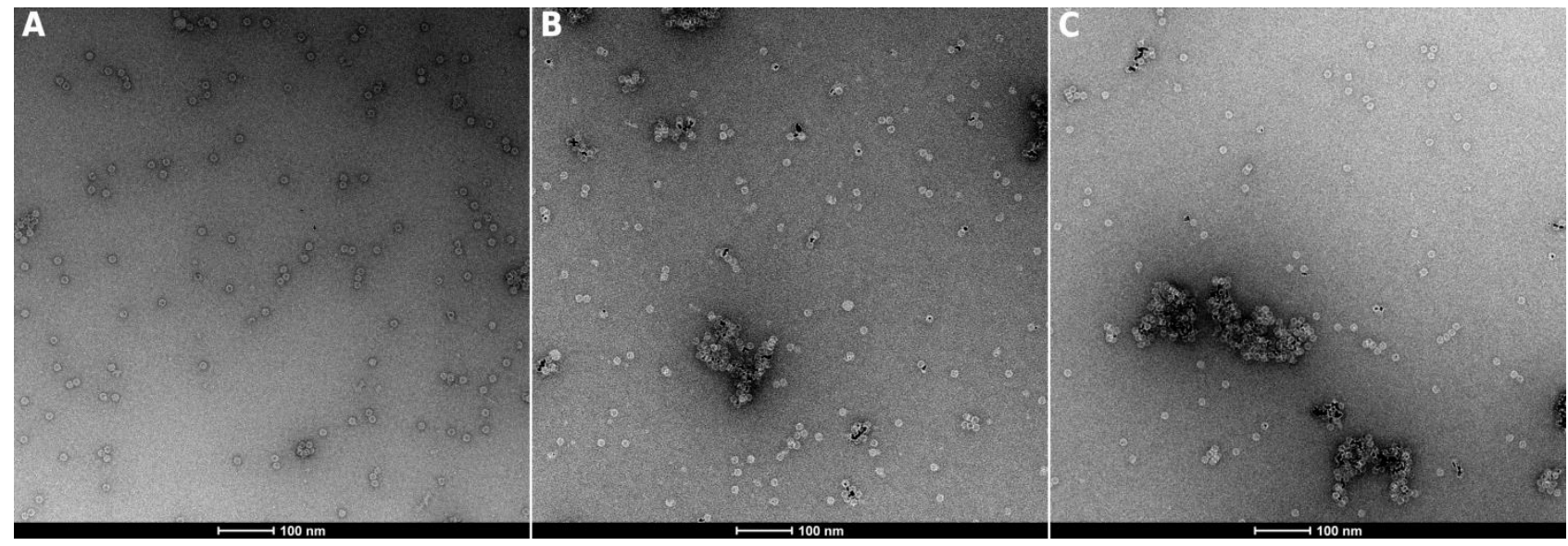

Figure 2 TEM-NS analysis of apoferritin incubation with $\mathrm{HAuCl}_{4}$ for $24 \mathrm{~h}$ after dialysis and before reduction $(\mathrm{A})$, after reduction $(\mathrm{B})$ and $72 \mathrm{~h}$ incubation $(\mathrm{C})$ 
The reactions of apoferritin with copper, palladium and nickel precursors are summarized in Figure 3.

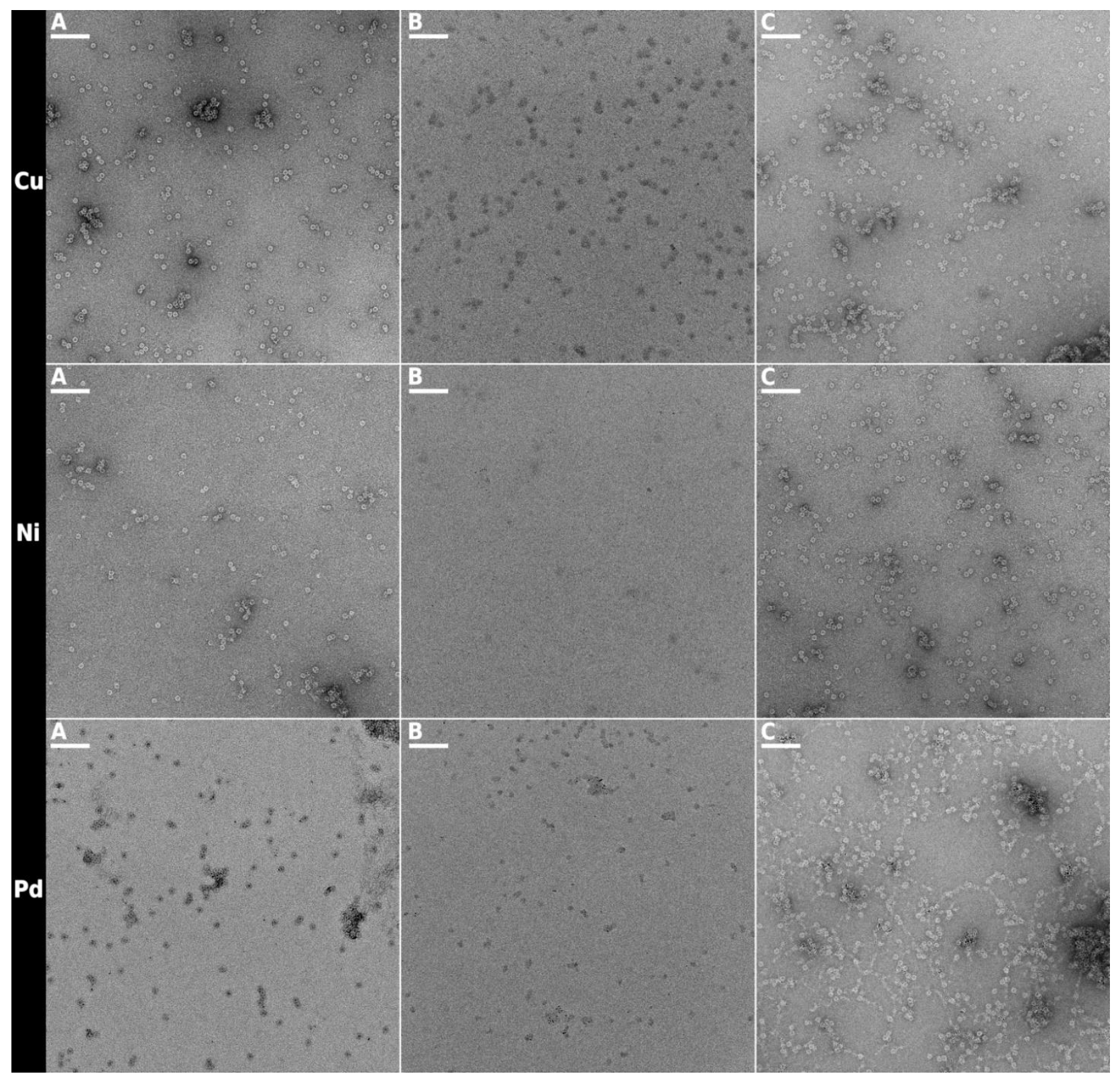

Figure 3 Summary of TEM analysis of apoferritin reacted with copper, nickel and palladium precursors from top to down. Columns A and B display negative and positive stained samples, respectively. Column C displays samples which were incubated $72 \mathrm{~h}$.

The reaction with copper (Cu-NP, Figure 3) reveals negligible amount of copper ions trapped by apoferritin cavities. Reaction mixture changed color from blue to reddish brown after adding of reducing agent. Negative stained sample characterized by TEM did not exhibit any visible metal signals located in apoferritin cavities. Positive staining EM data of the same sample showed small amount of metal nanoparticles which are intricately distinguishable from background. Long time incubation has not led to encapsulation of copper ions inside of apoferritin as shown in Figure 3-C.

Reaction mixture of apoferritin and nickel chloride changed color from blue-green to black after $\mathrm{NaBH}_{4}$ addition. Nickel nanoparticles (Ni-NPs) are present in larger quantities inside apoferritin cavity in comparison to CuNPs. We have observed very few Ni-NPs located inside of the apoferritin cavity, while the major part was 
detected outside of the apoferritin shell in concert with the observation we have made earlier for Au-NPs. Presence of Ni-NPs was further confirmed by positive staining EM (Figure 3-B) where nanoparticles with diameters ranging 13 to $53 \AA$ were observed. Prolonger incubation time has neither increased the portion of the nanoparticles present inside the apoferritin cavity, nor the diameter of the observed nanoparticles.

The results of the palladium nanoparticle (Pd-NP) preparation were similar to Ni-NPs. Reaction mixture changed color from original orange to dark brown or black after addition of $\mathrm{NaBH}_{4}$. TEM analysis showed the highest tendency for interaction between metal ions and apoferritin among the metals we have used. Similarly to previous cases, Pd-NPs were observed both on the outside and inside the apoferritin cavity. Longer incubation time probably led to denaturation of apoferritin (Figure 3-C). In addition to the apoferritin cage molecules, various small protein species and higher amount of palladium nanoparticles were present. Small protein particles probably aroused from apoferritin disassociation. These mono- or higher units interacted with palladium ions and formed various palladium-protein composites.

We have also performed apoferritin reaction with $\mathrm{HAuCl}_{4}$ in molar ratio $1: 20000$ at various $\mathrm{pH}$ values to understand its role in trapping of $\mathrm{Au}^{3+}$ ions in apoferritin cavity. Figure 4 summarizes reactions carried out at $\mathrm{pH}=4.19(\mathrm{~A}), 5.97(\mathrm{~B}), 7.88(\mathrm{C}), 9.39$ (D) $10.28(\mathrm{E})$, and incubation reaction at $\mathrm{pH}=10.28$ carried out for 72 hours (F). Reaction mixtures were reduced by $\mathrm{NaBH}_{4}$ (in molar ratio to $\mathrm{HAuCl}_{4} 5: 1$ ) which was added after $24 \mathrm{~h}$ of incubation. Dialyses were not performed. Reduction was accompanied by typical color change from original light yellow to final ruby. Reaction mixture carried out at pH 10.28 (Figure 4-F) spontaneously changed color from original light yellow to final ruby before $\mathrm{NaBH}_{4}$ addition.

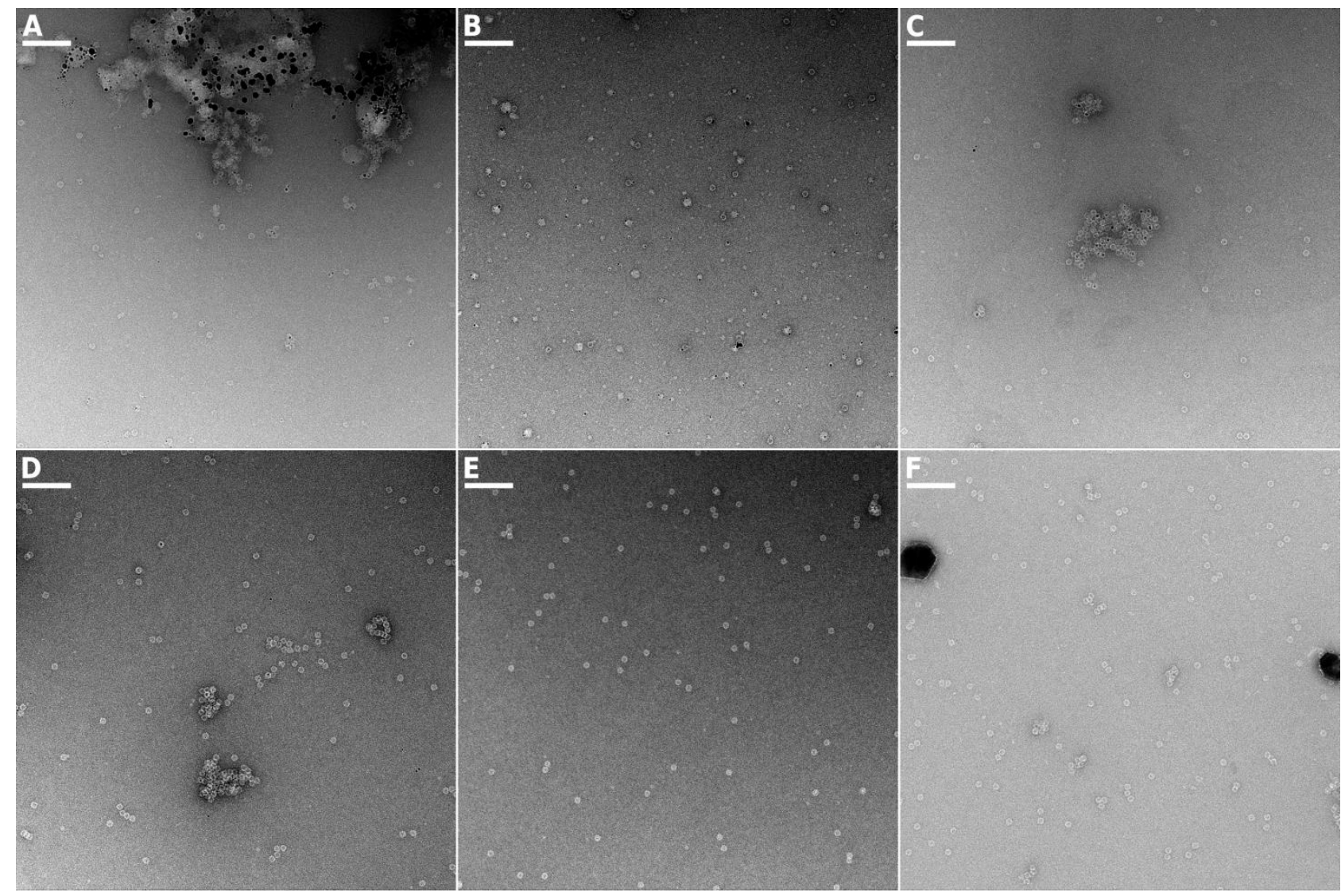

Figure 4 Summary of TEM analysis of apoferritin reacted with $\mathrm{HAuCl}_{4}$ at various $\mathrm{pH} . \mathrm{A}=4.19, \mathrm{~B}=5.97$, $\mathrm{C}=7.88, \mathrm{D}=9.39$ and $\mathrm{E}=10.28$. Figure $\mathrm{F}$ displays reaction under $\mathrm{pH}=10.28$ with incubation time $72 \mathrm{~h}$

The role of $\mathrm{pH}$ in nanoparticle formation was further monitored by TEM-NS (Figure 4). The reaction carried out at the lowest $\mathrm{pH}$ led to destabilization of apoferritin and formation of $\mathrm{Au}$ nanoparticles with broad size 
distribution. Nanoparticles were not located inside apoferritin cavities similarly as in the case of the reaction carried out at $\mathrm{pH} 6$ (Figure 4-B). However, the apoferritin degradation was observed to a lesser extent at $\mathrm{pH}$ 6 (Figure 4-B) with respect to reaction carried out at pH 4 (Figure 4-A). Almost none of the intact apoferritin molecules were occupied by Au nanoparticles which were primarily concentrated on the apoferritin degradation products. Size distribution of gold nanoparticles was noticeably narrower at $\mathrm{pH} 6$ than at $\mathrm{pH} 4$. The most promising results were obtained when the reaction was carried out at pH 8 (Figures 4-C,D). Au-NPs embedded in apoferritin shell form agglomerates in this case, but the apoferritin molecules remain intact. Reaction performed at $\mathrm{pH} 9$ led to similar results but apoferritin cavity is occupied by nanoparticles to lesser extent. In addition, small nanoparticle seeds were also observable outside of the apoferritin shell in this case. Increasing $\mathrm{pH}$ above 9 prevents uptake of the $\mathrm{Au}^{3+}$ ions into apoferritin cavities even for prolonged incubation time (Figures 4-E,F) [21]. On the contrary, large irregular Au-NPs were formed on the outside of the apoferritin cage in this case (Figure 4-F).

\title{
3. CONCLUSION
}

We have carried out a systematic study of the nanoparticle formation inside apoferritin cage using four different metal precursors (gold, copper, nickel and palladium). TEM analysis showed palladium nanoparticles which were formed in apoferritin cavities in the highest yield from all studied metals. The role of $\mathrm{pH}$ was described by TEM analysis when apoferritin was incubated with gold ions under different $\mathrm{pH}$ (in range of 4-10). Apoferritin was desaturated, disassociated and re-assembled into irregular species under the low $\mathrm{pH}$. Increasing of the $\mathrm{pH}$ led to accumulation of $\mathrm{Au}^{3+}$ ions in the apoferritin cavities. The reactions carried out at $\mathrm{pH} 7-9$ provided the largest content of metal ions inside the apoferritin cavity. None of the tested approaches resulted in homogeneously sized nanoparticles incorporated into the apofferitin cavity at high-yield and purity. Therefore, we conclude that this system for preparation of apoferritin-based nanoparticles is not suitable for production of biocompatible markers for electron microscopy.

\section{ACKNOWLEDGEMENTS}

\section{We acknowledge Cryo-Electron Microscopy and Tomography Core Facility of CIISB, Instruct-CZ Centre, supported by MEYS CR (LM2018127).}

This work is financially supported by TA ČR (project TN01000008)

\author{
We kindly thank to the Protex facility at the University of Leicester, Louise Fairall and Christos Savva \\ for using their plasmid LF2422
}

\section{REFERENCES}

[1] ZOU, Chang-dong, GAO, Yu-lai, YANG, Bin, ZHAI, Qi-jie. Size-dependent melting properties of Sn nanoparticles by chemical reduction synthesis. Transactions of Nonferrous Metals Society of China. [online]. 2010, vol. 20, no. 2, pp. 248-253. ISSN 10036326. Available from: https://doi.org/10.1016/S1003-6326(09)60130-8.

[2] WANG, Hongshui, QIAO, Xueliang, CHEN, Jianguo, WANG, Xiaojian, DING Shiyuan. Mechanisms of PVP in the preparation of silver nanoparticles. Materials Chemistry and Physics. [online]. 2005, vol. 94, no. 2-3, pp. 449453. ISSN 02540584. Available from: https://doi.org/10.1016/j.matchemphys.2005.05.005.

[3] ROSHANGHIAS, Ali, VRESTAL, Jan, YAKYMOVYCH, Andriy, RICHTER, W. Klaus, IPSER, Herbert. Sn-Ag-Cu nanosolders: Melting behavior and phase diagram prediction in the Sn-rich corner of the ternary system. Calphad. [online]. 2015, vol. 49, pp. 101-109 [cit. 2015-09-30]. ISSN 03645916. Available from:

https://doi.org/10.1016/i.calphad.2015.04.003.

[4] KIMLING, J., MAIER, M., OKENVE, B., KOTAIDIS, V., BALLOT, H., PLECH, A.. Turkevich Method for Gold Nanoparticle Synthesis Revisited. The Journal of Physical Chemistry B. [online]. 2006, vol. 110, no 3, pp. 1570015707. ISSN 1520-6106. Available from: https://doi.org/10.1021/jp061667w. 
[5] VYKOUKAL, Vit, HALASTA, Vitezslav, BABIAK, Michal, BURSIK, Jiri, PINKAS, Jiri. Morphology Control in AgCu Nanoalloy Synthesis by Molecular Cu(I) Precursors. Inorganic Chemistry. 2019, vol. 58, no. 22, pp. 15246-15254. ISSN 0020-1669. Available from: https://doi.org/10.1021/acs.inorgchem.9b02172.

[6] ZHANG, Yawen, HUANG, Wenyu, HABAS, Susan E., KUHN, John N., GRASS, Michael E., YAMADA, Yusuke, YANG, Peidong, SOMORJAI, Gabor A.. Near-Monodisperse Ni-Cu Bimetallic Nanocrystals of Variable Composition: Controlled Synthesis and Catalytic Activity for $\mathrm{H}_{2}$ Generation. The Journal of Physical Chemistry $\mathrm{C}$. [online]. 2008, vol. 112, no. 32, pp. 12092-12095. ISSN 1932-7447. Available from:

https://doi.org/10.1021/jp805788x.

[7] WAKUDA, D, KIM, KEUN-SOO, SUGANUMA, K. Room-Temperature Sintering Process of Ag Nanoparticle Paste. IEEE Transactions on Components and Packaging Technologies. [online]. 2009, vol. 32, no. 3, pp. 627632 [cit. 2015-04-18]. ISSN 1521-3331. Available from: https://doi.org/10.1109/TCAPT.2009.2015874.

[8] GINGU, Oana, ROTARU, P., MILEA, A., MARIN, A., NICOLICESCU, C., SIMA, Gabriela, TANASESCU, Speranta. In-situ synthesis of $\mathrm{AgCu} / \mathrm{Cu}_{2} \mathrm{O}$ nanocomposite by mechanical alloying: The effect of the processing on the thermal behavior. Thermochimica Acta. [online]. 2015, vol. 606, pp. 1-11. ISSN 00406031 . Available from: https://doi.org/10.1016/j.tca.2015.03.002.

[9] GÎNGU, Oana, NICOLICESCU, Claudiu, SIMA, Gabriela. Research of the Milling Time Influence on Ag-Cu Powder Particles Size Processed by Mechanical Alloying Route. Solid State Phenomena. [online]. 2012, vol. 188, pp. 382-387. ISSN 1662-9779. Available from: https://doi.org/10.4028/www.scientific.net/SSP.188.382.

[10] KIM, Chang Kyu, LEE, Gyoung-Ja, LEE, Min Ku and RHEE, Chang Kyu. A novel method to prepare Cu@Ag core-shell nanoparticles for printed flexible electronics. Powder Technology. [online]. 2014, vol. 263, pp. 1-6. ISSN 00325910. Available from: https://doi.org/10.1016/i.powtec.2014.04.064.

[11] JUNG, Inyu, JO, Yun Hwan, KIM, Inyoung and LEE, Hyuck Mo. A Simple Process for Synthesis of Ag Nanoparticles and Sintering of Conductive Ink for Use in Printed Electronics. Journal of Electronic Materials. [online]. 2012, vol. 41, no. 1, pp. 115-121. ISSN 0361-5235. Available from: https://doi.org/10.1007/s11664-011$\underline{1761-3 .}$.

[12] KELLY, K. Lance, CORONADO, Eduardo, ZHAO, Lin Lin and SCHATZ, George C. The Optical Properties of Metal Nanoparticles: The Influence of Size, Shape, and Dielectric Environment. The Journal of Physical Chemistry B. [online]. 2003, vol. 107, no. 3, pp. 668-677. ISSN 1520-6106. Available from: https://doi.org/10.1021/jp026731y.

[13] BROZ, Pavel, HEJDUKOVA, Martina, VYKOUKAL, Vii, ZELENKA, Frantidek, SOPOUSEK, Jiri, BURSIK, Jiri and ZOBAC, Ondrej. Study of surface effects and catalytic properties of selected Ni-based bimetallic nanoparticles by Knudsen effusion mass spectrometry. Calphad. [online]. 2019, vol. 64, pp. 334-341. ISSN 03645916. Available from: https://doi.org/10.1016/i.calphad.2019.01.013.

[14] PAGE FAULK, W a MALCOLM TAYLOR, G. Communication to the editors. Immunochemistry. [online]. 1971, vol. 8, no. 11, pp. 1081-1083. ISSN 00192791. Available from: https://doi.org/10.1016/0019-2791(71)90496-4.

[15] ZHONG, Ling, BROWN, Joshua C., WELLS, Clive a GERGES, Nashaat Z. Post-embedding Immunogold Labeling of Synaptic Proteins in Hippocampal Slice Cultures. Journal of Visualized Experiments. [online]. 2013, no. 74. ISSN 1940-087X. Available from: https://doi.org/10.3791/50273.

[16] MAITY, Basudev, HISHIKAWA, Yuki, LU, Diannan and UENO, Takafumi. Recent progresses in the accumulation of metal ions into the apo-ferritin cage: Experimental and theoretical perspectives. Polyhedron. [online]. 2019. ISSN 02775387. Available from: https://doi.org/10.1016/i.poly.2019.03.048.

[17] JUTZ, Günther, VAN RIJN, Patrick, SANTOS MIRANDA, Barbara and BÖKER, Alexander. Ferritin: A Versatile Building Block for Bionanotechnology. Chemical Reviews. [online]. 2015, vol. 115, no. 4, pp. 1653-1701. ISSN 0009-2665. Available from: https://doi.org/10.1021/cr400011b.

[18] GÁlVEZ, Natividad, FERNANDEZ, Belen, VALERO, Elsa, SÁNCHEZ, Purificación, CUESTA, Rafael and DOMÍNGUEZ-VERA, José M. Apoferritin as a nanoreactor for preparing metallic nanoparticles. Comptes Rendus Chimie. [online]. 2008, vol. 11, no. 10, pp. 1207-1212. ISSN 16310748. Available from: https://doi.org/10.1016/i.crci.2008.09.003. 
[19] DOMÍNGUEZ-VERA, José M., GÁLVEZ, Natividad, SÁNCHEZ, Purificación, MOTA, Antonio J., TRASOBARES, Susana, HERNÁNDEZ, Juan C. a CALVINO, Jose J. Size-Controlled Water-Soluble Ag Nanoparticles. European Journal of Inorganic Chemistry. [online]. 2007, no. 30, pp. 4823-4826. ISSN 14341948. Available from: https://doi.org/10.1002/ejic.200700606.

[20] MAITY, Basudev, HISHIKAWA, Yuki, LU, Diannan and UENO, Takafumi. Recent progresses in the accumulation of metal ions into the apo-ferritin cage: Experimental and theoretical perspectives. Polyhedron. [online]. 2019, vol. 172, pp. 104-111. ISSN 02775387. Available from: https://doi.org/10.1016/i.poly.2019.03.048.

[21] KONG, Bo, HUANG, He-Qing, LIN, Qing-Mei, CAI, Zong-Wei and CHEN, Ping. Effect of pH and Phosphate on Trapping Capacity of Various Heavy Metal lons With Ferritin Reactor in Flowing Seawater. Applied Biochemistry and Biotechnology. [online]. 2005, vol. 126, no. 2, pp. 133-148. ISSN 0273-2289. Available from: https://doi.org/10.1385/ABAB:126:2:133. 